practitioner, except a specialist physician, knows. The approach to the disease is, of course, that which is expected from tuberculosis physicians, but it is an approach which is rare in others. This is an ideal book for a medical officer of a sanatorium or a young tuberculosis officer, because in a small space it gives the background of years of experience of tuberculosis work.

After this genuine recommendation of the book as a whole it may seem ungracious to pick holes.

The chapter on Pathology is a rather queer mixture of fact and theory and is, perhaps, unnecessarily complicated. The chapter on examination of the patient contains descriptions of all the usual physical signs-presumably this is a conventional necessity. It would have done a better service to the tuberculous patient if it were pointed out that physical signs are of two kinds-those one hears before seeing the chest X-ray and those one hears after seeing the chest X-ray, and the latter are more reliable. It could not have been stated too strongly that early tuberculosis usually shows no physical signs and the only method of diagnosing early tuberculosis is by X-raying the chest. The old idea, "If there are no physical signs, there is no need for an X-ray"-like all old ideas, dies hard. Here was an opportunity to give it the coup de grace. The sections on treatment are admirable, even if in a few instances, notably in the radical treatment of tuberculous pyothoraces, the views expressed are at variance with those of the reviewer. Again the illustrations of X-rays showing the various forms of collapse therapy deserve a special word to themselves; they are excellent.

As stated before, nothing is left out. There is even a paragraph on that thorny subject Rehabilitation, which was skated over-perhaps wisely! If our efforts were directed more to early diagnosis and even more to immediate treatment of tuberculosis, the word Rehabilitation might be forgotten within a few years.

\section{HYGIENE (2nd Edition)}

By J. R. Currie, M.A., M.D., LL.D., D.P.H., F.R.C.P. and A. C. MEarNes, B.Sc., M.D., D.P.H., F.R.S. Published by E. \& S. Livingstone, Ltd., Edinburgh. 1945. 89 Figures. Price 2Is.

One welcomes the new edition of this book. As the authors state, in the endeavour to keep pace with the quickened development of public health and social medicine, most of the book has been recast and much new material added including a postscript on post-war design - of dwellings, also a brief but very lucid outline of the National Insurance Bill.

The general lay-out and theme of the book remains much the same but with new matter added, in addition to many new and helpful illustrations, some being in colour. It is not a case of "just another book on hygiene"; in many respects it differs fundamentally from the usual type in its variety of arrangement and mode of approach.

Priority has been given throughout to the social aspect of hygiene. The book opens with a general survey of the history of hygiene and contains much useful and constructive information, tracing, as it does under appropriate sub-sections, how hygiene from its earliest conception of personal hygiene, to-day embraces preventive, curative and social medicine. Much useful advice is given to those about to commence general practice, and to those already in it, under the sub-section "Medical Practice." The recommendation that the practitioner should seek the assistance of local authorities' medical services and keep himself informed of those services which are available to him, is significant in view of present-day tendencies. The general arrangement and approach to the subject is probably unique, in that the career and hazards of the individual are followed in relation to the social services from his inheritance, through his infant and childhood days, through schooling to his adult and working days. Finally old age and old age pensions are dealt with.

The section on "Inheritance" giving the essentials of the science of genetics and applied genetics is an innovation, a gentle reminder to the medical student that, having completed his study of biology, he can no longer dismiss this subject entirely to the background. Much is heard to-day of "Positive Health" and whatever interpretation is placed upon this, it seems doubtful whether the ideal can possibly be obtained without some improvement of the stock. The authors wisely point out that even if some form of eugenics was put into operation, in the present state of our knowledge, the effect would be negatived by the inscrutable heterozygotes who would continue to transmit their hereditary defects.

Other sections of the look which are worthy of note are those dealing with industrial hygiene, food, infection, prevention and community diseases, for the clear and masterly way in which the subjects are approached. The section on housing includes a sub-section on post-war planning and post-war housing.

Each section or chapter dealing with individual subjects opens with a short explanatory paragraph and is succeeded by suitably headed sub-sections. These subsections contain practically all the essentials that a student should know. In these days of intensive study the already overburdened medical student is justified in expecting the help of his teachers in sorting the "wheat from the chaff," and this, Professor Currie and Doctory Mearns have accomplished in an admirable, yet most interesting and readable manner.

Of adverse criticism there is little, but it is a pity that in an up-to-the-minute book such as this, no mention has been made of two important new additions to our preventive and treatment armamentarium, viz.:-D.D.T. (dichlor-diphenyl-trichlorethane) and Penicillin, the former in connection with anti-louse and anti-malarial campaigns and the latter in respect of the revolutionary changes it has produced both in medicine and surgery relative to conditions caused by Penicillin sensitive organisms. It is to be hoped that these omissions will be made good in an early reprint of the book.

Generally the book is intended for students of medicine, general practitioners and workers in hygiene, to whom it can be highly recommended. It is written in a clear, easy style which holds one's attention and interest throughout, moreover, there are few or no irritating cross-references or references to Acts of Parliament to distract the attention of the reader. All references to Public Health Acts and ministerial regulations are included in the text, in easy and understandable language.

The authors have undoubtedly succeeded in their task of presenting to students in a readable and attractive manner the importance of the subject they practice and teach. The wealth of information contained in just over 400 pages is amazing.

Lastly, a word of praise to the publishers for an excellent publication at a difficult time, attractively bound, good paper, clear printing and illustrations, and the whole work being well indexed. 